\title{
A implantação de cotas na universidade: paternalismo e ameaça à posição dos grupos dominantes
}

\author{
MARCUS EUGÊNIO OLIVEIRA LIMA \\ Universidade Federal de Sergipe, \\ São Cristóvão, SE, Brasil \\ PAULO SÉRGIO DA COSTA NEVES \\ Universidade Federal de Sergipe, \\ São Cristóvão, SE, Brasil
}

PAULA BACELLAR E SILVA Universidade Federal da Bahia, Salvador, BA, Brasil

\section{INTRODUÇÃO}

Ações afirmativas consistem em políticas públicas ou privadas que possuem o objetivo de neutralizar os efeitos da discriminação de raça, gênero, idade, nacionalidade, aspectos físicos (Gomes, 2003) e existem quando uma organização investe em recursos (dinheiro e tempo) para evitar que pessoas sofram essa diferenciação com base em seu gênero ou grupo étnico (Crosby; Iyer; Sincharoen, 2006).

Dessa maneira, a ação afirmativa tem o objetivo de criar oportunidades iguais de modo proativo. A prática mais conhecida de ação afirmativa é o sistema de cotas, que consiste em "estabelecer um determinado número ou percentual a ser ocupado em área específica por grupo(s) definido(s), o que pode ocorrer de maneira proporcional ou não, e de forma mais ou menos flexível" (Moehlecke, 2002, p. 199).

No Brasil, as primeiras medidas de ação afirmativa do tipo cotas foram voltadas para a promoção da entrada de deficientes físicos no mercado de trabalho 
(Brandão, 2005). Em 1996, no governo de Fernando Henrique Cardoso, pela primeira vez foi considerada a possibilidade de implantação de políticas de ação afirmativa no nível federal. No entanto, o assunto foi esquecido, sendo retomado apenas depois de pressões da sociedade civil e de movimentos sociais organizados (Telles, 2006).

Em 2001 foram dados os primeiros passos para a implementação de reserva de vagas em instituições públicas de ensino superior pelas universidades estaduais da Bahia, Rio de Janeiro e Mato Grosso do Sul (Silva, 2007). A primeira universidade federal a adotar cotas para negros e índios foi a Universidade de Brasília (UnB), em 2004. Em 2007, um levantamento feito pelo Laboratório de Políticas Públicas (LLP) da Universidade do Estado do Rio de Janeiro (UERJ) indicou que 51 instituições de ensino já haviam adotado políticas de ação afirmativa, entre universidades estaduais e federais, faculdades, centros universitários e institutos federais superiores (IFS) (LPP/UERJ, 2009).

Ainda que a primeira lei (n. 3.708; Rio de Janeiro, 2001) responsável pela criação das cotas nas universidades tenha completado 10 anos e que desde 2003 tenhamos cotistas e não cotistas convivendo nos cursos, poucas pesquisas têm analisado o desenvolvimento das atitudes dos estudantes em relação às cotas. Com efeito, parte das pesquisas analisa a convivência e relações pessoais entre cotistas e não cotistas (e.g., Nery; Costa, 2009); outras se centram nas consequências racializadoras das cotas (e.g., Maggie, 2005) ou, ainda, na oposição dos cidadãos comuns às cotas, por estas ameaçarem o mito da democracia racial (e.g., Oliveira Filho, 2009); enquanto outras enfocam os aspectos mais formais e jurídicos das políticas de ação afirmativa na educação (e.g., Santana, 2010) ou as percepções e atitudes de pré-vestibulandos e outros alunos do ensino médio (e.g., Brandão; Marins, 2007; Neves; Lima, 2007; Vasconcelos; Silva, 2005) e o modo como estudantes negros beneficiados pelo sistema de cotas avaliam esta política (e.g., Bittar; Almeida, 2006).

Dessa maneira, comparativamente, poucos estudos têm enfocado a evolução das atitudes em relação às cotas antes e depois de sua implantação. Um aspecto importante, uma vez que a análise da evolução das atitudes em relação a um objeto social ajuda a melhor entender como este é significado e ressignificado, legitimando ou contestando as primeiras atitudes (Wood, 2000).

Uma importante exceção é o estudo de Queiroz e Santos (2006), o qual, citando dados de 1995 e 2006 do Instituto Datafolha, observa que a população brasileira tem se tornado mais favorável às cotas sociais e raciais.

No presente estudo, analisamos as atitudes perante as cotas sociais e raciais de estudantes dos cursos mais concorridos da Universidade Federal de Sergipe (UFS) antes da implantação de cotas em 2005, época de intenso debate sobre o tema, e depois de sua implantação, na primeira turma de cotistas em 2010. Seguindo Blumer (1958), nossa hipótese principal propõe que a entrada de cotistas produziu ameaça à posição de dominação dos não cotistas, o que tornará mais contrárias as atitudes desse último grupo perante as cotas. Formulamos ainda uma hipótese complementar, dessa vez seguindo as ideias de Allport (1954/1979) sobre o contato 
como redutor do preconceito, propondo que, quanto maior o nível de contato entre cotistas e não cotistas, mais favoráveis estes se tornarão às cotas.

\section{POSIÇÃO DOS GRUPOS, DOMINAÇÃO E PATERNALISMO}

O debate sobre a implantação de políticas de ações afirmativas levanta preocupações com a justiça. Os julgamentos sobre a justiça fazem a mediação entre as circunstâncias objetivas e as reações das pessoas aos eventos particulares de tal forma que o modo como os cidadãos comuns avaliam as normas, se justas ou injustas, é um tema de interesse especial para as ciências sociais, pois os padrões de justiça são resultado dos processos de construção da realidade social (Tyler, 2006). Um campo de particular interesse para estudar as percepções de justiça e legitimação da ordem estabelecida é o das relações raciais, pela forte assimetria de poder e dominação que as têm caracterizado ao longo da história.

Seguindo a análise de Winant (2000), podemos conceber três grupos de teorizações sobre as raças nas ciências sociais: a) as teorias da etnicidade, que sugerem que as atitudes preconceituosas podem ser combatidas com o contato, a integração e a assimilação dos grupos; sendo a raça entendida no quadro cultural geral da identidade coletiva; $b$ ) as teorias baseadas na classe, que concebem o racismo como consequência da competição entre os grupos e da estratificação econômica, de maneira que, para combatê-lo, é necessário criar programas que estimulem a consciência racial e diminuam as desigualdades econômicas, a exemplo dos programas de ação afirmativa; c) as teorias baseadas na nação, que concebem a raça em termos geopolíticos, pondo ênfase no pertencimento coletivo numa unidade que integre raça e nação, o que pode conduzir a fenômenos como o nazifascismo.

Na psicologia social, as teorias do primeiro tipo são analisadas na abordagem pioneira de Allport (1954/1979) sobre os efeitos do contato intergrupal na redução do preconceito. De acordo com essa abordagem, o contato com o "outro diferente" reduz o preconceito quando são cumpridas as seguintes regras: a) que os grupos possuam igualdade de status na interação; b) que desenvolvam atividades de cooperação com objetivos comuns; c) que as relações sejam próximas e personalizadas e d) que haja apoio das normas e autoridades para o contato. Quando todas essas condições são garantidas, o contato reduz o preconceito (Lima, 2011, para uma revisão). Com efeito, uma meta-análise de 203 estudos sobre a relação do contato com o preconceito constatou que em $94 \%$ dos casos o contato reduzia o preconceito (Pettigrew; Tropp, 2006).

As teorias do segundo tipo, que enfatizam a relação entre raça, preconceito e classe, são desenvolvidas na própria sociologia por Herbert Blumer, com a sua teoria do senso de posição grupal (sense of group position theory). Blumer (1958) propõe que o preconceito racial existe basicamente como resultado de relações que ameaçam o poder ou a dominação de um grupo sobre o outro. Assim, o sentimento mais comum no preconceito racial é o de que o grupo subordinado está ameaçando 
ou poderá ameaçar a posição do grupo dominante. De acordo com Blumer (1958, p. 4, tradução nossa):

O grupo dominante não está preocupado com o grupo dominado como tal, mas ele está profundamente preocupado com sua posição vis-à-vis o grupo subordinado. Isso é epitetomizado numa expressão universal: "está tudo certo quando cada raça está em seu lugar”.

Esse senso de posição grupal é um produto histórico que se define pelas condições iniciais de contato entre os grupos, nas quais o prestígio, o poder e a posse de meios, intenções, desígnios, entre outros, são os elementos constituintes essenciais. Como referem Bobo e Hutchings (1996), as teses sobre a posição do grupo enfatizam o nível de ameaça que os membros do grupo dominante sentem de perderem seus direitos e recursos para outros grupos sociais. De acordo com esses autores, ainda que a percepção de ameaça e competição grupal envolva fatores genuinamente psicológicos, ela não pode ser explicada somente por estes.

A teoria da dominância social encontra suporte empírico para essas asserções em estudos feitos nos Estados Unidos (Sidanius; Pratto, 1999). Outra teoria derivada das ideias de Blumer é a teoria da justificação do sistema, segundo a qual os estereótipos são uma forma de justificação dos arranjos sociais como legítimos, tendo, portanto, a função de preservar o status quo das relações (Jost; Banaji, 1994). Pereira, Vala e Costa-Lopes (2010) encontram ampla evidência do papel da justificação no preconceito contra os imigrantes na Europa. Mas que recursos são mobilizados pelos grupos dominantes para manter suas posições em relações de intenso contato e longa duração, como as raciais?

As teses do paternalismo nos permitem entender melhor as relações entre contato e senso de posição grupal. Jackman (1994) desenvolve esse postulado criando sua teoria da dominação paternalista. De acordo com a referida autora, a dominação opera mais como resultado de uma persuasão ideológica dos dominantes para manter suas posições que por meio do conflito aberto e controle explícito, sobretudo em relações de exploração de longa duração. A ideia central dessa teoria se inspira nas reflexões de Max Weber sobre a docilização dos dominados. Para Weber (1947/1993), as formas genuínas de dominação implicam a submissão voluntária, isto é, a interiorização da obediência como um princípio.

Assim, os beneficiados com as relações desiguais procuram significar a exploração e expoliação de modo que estas pareçam legítimas tanto para eles e sua consciência mormente cristã quanto para aqueles que estão sendo explorados. Para tanto, utilizam a persuasão mais que a força, uma vez que esta seria um meio oneroso e falho de manter o poder por longo tempo. A persuasão carinhosa, adocicada, carregada de afetos para com os dominados é para Jackman (1994, p. 9) o paternalismo, a mais efetiva forma de domínio: "The sweetest persuasion: paternalism".

A ideia central do argumento de Jackman (1994) é a de que, num mundo de recursos finitos, a desigualdade entre os grupos significa necessariamente que um explora ou expropria o outro. Então, se faço parte do grupo dominante, aquele 
que possui mais prestígio, status, dinheiro e privilégios sociais, dar ou conceder benefícios ao grupo subordinado implica tirar aquilo que é do meu grupo. É nesse sentido que, para manter suas posições privilegiadas, os grupos dominantes utilizam a ideologia do paternalismo.

Assim, trata-se de uma forma de discriminação sem hostilidade, que envolve o sentimento de benevolência, mas ao mesmo tempo de controle (idem). A autora descreve as relações dos senhores brancos com seus escravos no sul dos Estados Unidos para situar as origens históricas do fenômeno. Mais próximo do nosso contexto, podemos lembrar as teses de Gilberto Freyre em Casa-grande e senzala (1933/1983, p. 191) sobre o colonizador português: "um espanhol sem a flama guerreira nem a ortodoxia dramática; um inglês sem as duras linhas puritanas. $\mathrm{O}$ tipo do contemporizador. Nem ideais absolutos, nem preconceitos inflexíveis".

O paternalismo, enquanto ideologia da domesticação, não foi superado com o desenvolvimento das democracias. A esse respeito, basta analisar a ampla evidência empírica da teoria do sexismo benevolente (e.g., Glick; Rudman, 2010). Aqui no Brasil, Oliveira Filho (2009) verifica que o discurso de cidadãos brancos contra as cotas raciais se baseia na crença de que as cotas racializam o Brasil, dividindo de modo forçado um país miscigenado. Ou seja, a oposição ao avanço dos grupos se justifica pela tentativa de proteger esses mesmos grupos de viverem numa sociedade cindida e racializada.

Contudo, cabe referir que a benevolência nas relações intergrupais de dominação é apenas aparente, pois a pressuposição de superioridade moral de um grupo sobre outro nada tem de benévola (Jackman, 1994). É nesse sentido que o paternalismo se torna um tipo de preconceito, pois concebe o outro como menos dotado moralmente.

Neste artigo, apresentamos dois estudos feitos com estudantes universitários dos cursos mais elitizados economicamente e de difícil acesso da UFS. Em ambos, perguntamos sobre as atitudes em relação às cotas para pobres e para negros e sobre percepções de justiça social. O primeiro estudo foi feito antes da implantação das cotas, quando estas ainda eram uma expectativa e, portanto, representavam uma ameaça moderada ou baixa. O segundo estudo foi feito depois dos primeiros momentos da entrada dos cotistas negros e pobres nos antes muito restritivos corredores desses cursos, tornado real e elevada a ameaça à posição dos grupos. A nossa hipótese principal prevê mais oposição às cotas no segundo momento e, ao mesmo tempo, uma influência moderadora do contato com os não cotistas, i.e., quanto mais contato com eles, menos contrária a atitude perante as cotas.

\section{ESTUDO 1: ATITUDES PERANTE AS COTAS ANTES DE SUA IMPLANTAÇÃO}

Este estudo foi realizado em 2005, um ano que fora significativo nos debates sobre cotas na UFS, uma vez que várias instituições federais de ensino superior (IFES) próximas começavam a implantar o sistema, a exemplo da Universidade 
Federal da Bahia (UFB), que o instituiu em 2004 e teve sua primeira turma em 2005. Assim, a reitoria da UFS começou a formar os grupos de estudo para a implantação do sistema de cotas e uma série de eventos e debates sobre o tema começou a ganhar corpo na academia e também fora dela. A recuperação foi tanta que, no primeiro semestre de 2006, os cursinhos pré-vestibulares realizaram passeatas contra as cotas nas ruas do centro de Aracaju. Foi nesse contexto que realizamos este estudo no segundo semestre de 2005 na UFS, com uma amostra representativa dos alunos da instituição (Neves; Lima, 2007). No presente artigo, analisamos os dados de cinco dos cursos mais concorridos no vestibular daquele ano: medicina, direito, psicologia, odontologia e enfermagem.

\section{MÉTODO}

\section{Participantes}

Foram 220 estudantes participantes: 32,3\% de medicina, 27,7\% de psicologia, 20,9\% de direito, $11,8 \%$ de enfermagem e 7,3\% de odontologia. A maioria de sexo feminino (63,3\%), com idade variando entre 18 e 44 anos $(M=22 ; D P=$ 3,54\%). Dos participantes, $63,9 \%$ possuíam renda familiar mensal superior a dez salários mínimos. Em relação à cor da pele autodeclarada, utilizando a classificação do Instituto Brasileiro de Geografia e Estatística (IBGE), verificamos que 1,4\% se definiu como indígena, $5 \%$ como pretos, $6,8 \%$ como amarelos, $34,2 \%$ como brancos e $44,7 \%$ como pardos. Outros, $7,9 \%$, não escolheram essas cores para se autodefinirem.

\section{Procedimentos e instrumentos}

Em uma sala de aula, os estudantes responderam a um questionário com perguntas abertas e fechadas, no qual indagávamos sobre percepções de justiça social e atitudes perante as cotas. Especificamente, pedimos para que os participantes avaliassem a situação econômica dos negros no Brasil em relação aos brancos, numa escala de cinco intervalos (1- muito melhor ; 5- muito pior); que avaliassem a justiça dessa situação (1- totalmente justa; 4- totalmente injusta); que indicassem suas atitudes perante as cotas sociais e raciais (1- favorável; 2 - sem posição definida; 3- contrários) e que justificassem essas atitudes numa questão aberta. Para análise dessa última questão, seguimos os pressupostos de Bardin (1979). Os dados foram analisados por meio do programa SPSS, software aplicativo do tipo científico. Todos os procedimentos éticos prescritos na resolução n. 196/1996 do Conselho Nacional de Saúde (CNS) foram seguidos e os termos de consentimento assinados pelos participantes.

\section{Resultados e discussão}

Quando instados a avaliar a situação econômica dos negros em relação aos brancos no Brasil e a legitimidade dessa situação, os estudantes não tiveram dúvidas sobre o fato de os negros viverem numa situação pior que a dos brancos. As respostas 
giraram em torno das categorias "pior" e "muito pior" e foram transversais à cor da pele, isto é, não foram influenciadas por ela, $F(2,178)<1$, n.s.

Todavia, existiu um impacto significativo da cor da pele nas avaliações da justiça da situação de assimetria econômica entre negros e brancos, $F(2,173)=$ $4,59, p=.01$, os pretos consideraram menos injusta a situação dos negros que os brancos e pardos (Tabela 1 ).

Tabela 1 - Médias e desvios padrões da percepção de justiça social em virtude da cor da pele (2005)

\begin{tabular}{l|r|r|r|r}
\hline \multicolumn{1}{c|}{ Percepção de justiça social } & Brancos & Pardos & \multicolumn{1}{c|}{ Pretos } & \multicolumn{1}{c}{ Total } \\
\hline $\begin{array}{l}\text { Como avalia a situação econômica dos } \\
\text { negros no Brasil em relação aos brancos?* }\end{array}$ & $\begin{array}{r}4,25 \\
(0,74)^{* * *}\end{array}$ & $\begin{array}{r}4,27 \\
(0,58)\end{array}$ & $\begin{array}{r}4,0 \\
(0,63)\end{array}$ & $\begin{array}{r}4,25 \\
(0,65)\end{array}$ \\
\hline $\begin{array}{l}\text { Você acabou de avaliar a situação dos } \\
\text { negros em relação aos brancos. Como }\end{array}$ & $\begin{array}{r}3,50 \mathrm{a} \\
(0,58)\end{array}$ & $\begin{array}{r}3,37 \mathrm{a} \\
(0,70)\end{array}$ & $\begin{array}{r}2,80 \mathrm{~b} \\
(1,13)\end{array}$ & $\begin{array}{r}3,39 \\
(0,70)\end{array}$ \\
\hline
\end{tabular}

Fonte: Banco de dados da pesquisa.

Elaboração dos autores.

* A escala variava de: 1 (muito melhor), 2 (melhor), 3 (igual), 4 (pior) e 5 (muito pior).

* A escala variava de: 1 (totalmente justa), 2 (justa), 3 (injusta) e 4 (totalmente injusta).

*** Entre parênteses consta o desvio padrão.

Nota: Médias com letras diferentes são significativamente diferentes (Student Newman Keuls $-S N K, p<.05$ ).

Causa alguma estranheza que os brancos tenham considerado a situação dos negros mais injusta que eles próprios julgaram. Uma explicação já clássica no racismo do Brasil seria afirmar que se trata de preconceito dos negros contra eles mesmos. Todavia, essa tese - que revitimiza a vítima, tornando-a culpada pelo próprio sofrimento - não se sustenta, uma vez que, quando indagamos sobre o orgulho em relação à cor da pele, observamos que os negros sentiam mais orgulho $(M=4,56)$ que os pardos $(M=4,28)$ e brancos $(M=3,47)$, esses de modo indiferenciado, $F(2,151)=9,11, p<.001 .^{1}$

Outra explicação possível, que nos parece mais apropriada, deriva das teorias sobre as expressões "benevolentes" do preconceito, especificamente as teses sobre o paternalismo que afirmam que os grupos dominantes reconhecem o preconceito e as injustiças sociais, reconhecem publicamente o desejo de proteger ou ajudar as minorias, como um pai faz com os filhos, mas simultaneamente não se mostram interessados em alterar sua posição de dominação (Jackman, 1994). Trata-se de um "refinamento ideológico" que enfatiza, por um lado, o alto suporte para a igualdade entre todos e, por outro, o baixo apoio aos programas de ação afirmativa que reduzam as desigualdades raciais (Quillian, 2006). Essa tese será avaliada em seguida, quando analisarmos as atitudes perante as cotas.

1 A pergunta feita no início do questionário depois da autodefinição de cor era: "Em que medida sente orgulho da cor da sua pele?” A escala variava de 1 (nenhum) a 5 (total). 
Para as análises que se seguem, agregamos pretos e pardos na categoria "negros", uma vez que as políticas de ação afirmativa em análise estão dirigidas a essa categoria social.

Quando indagados sobre suas atitudes em relação às cotas sociais, i.e., para estudantes de escolas públicas, na média os estudantes se mostraram contrários em $67 \%$ dos casos. Apenas $24,1 \%$ foram favoráveis e $9 \%$ não se posicionaram (Figura 1). Esse resultado não sofreu influência da cor da pele dos respondentes, $X^{2}(2, \mathrm{n}=220)<1, \mathrm{n}$.s. Ainda mais contrários se mostraram os estudantes quando indagados sobre suas atitudes em relação às cotas raciais, i.e, para pretos e pardos nas universidades públicas. Apenas $9,8 \%$ afirmaram ser favoráveis a essa modalidade de cotas, 83,6\% foram contrários e 6,6\% sem posição definida. Na Figura 1 podemos ver que novamente não houve efeito da cor da pele dos respondentes, $X^{2}(2, \mathrm{n}=220)<1$, n.s.

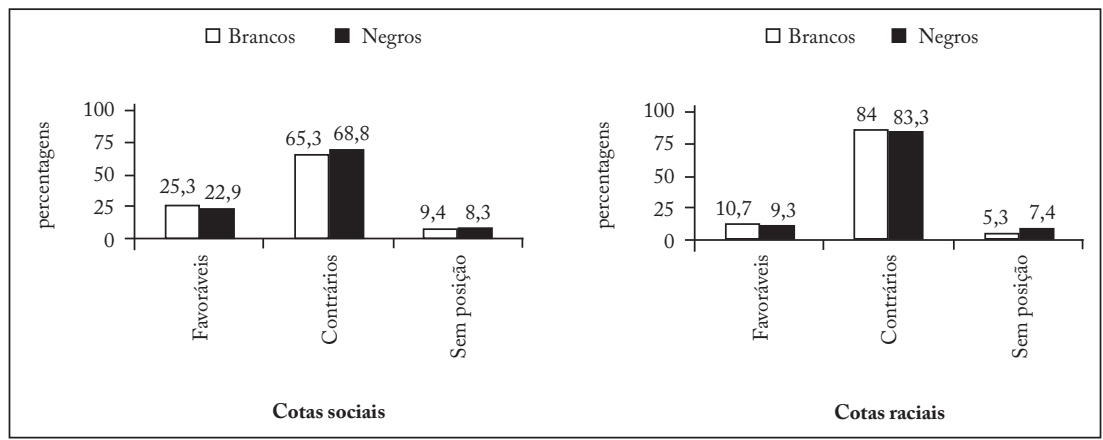

Figura 1 - Atitudes perante as cotas sociais e raciais nas universidades públicas em virtude da cor de pele dos participantes (2005) (dados em percentagens).

Fonte: Banco de dados da pesquisa.

Elaboração dos autores.

Um elemento essencial para entendermos as atitudes é a análise das retóricas ou discursos que as justificam e estruturam. Como refere Billig (2008), as atitudes não são construtos internos daqueles que as mantêm, pelo contrário, elas têm sentidos externos e retóricos; possuir uma atitude é tomar partido em uma questão polêmica. Isso fica claro quando analisamos os principais argumentos contrários e favoráveis às cotas produzidos pelos estudantes. Os contrários afirmaram que "elas aumentam o preconceito"; os favoráveis, por seu turno, disseram que "elas promovem justiça social" e que "combatem o preconceito" (Tabela 2). Trata-se aqui de um campo dilemático no qual os mesmos elementos retóricos, mas em sentido inverso, são usados por grupos em oposição para justificar suas atitudes. Nos discursos que constituem a realidade social, é comum que argumentos aparentemente contrários sejam usados (Billig et al., 1988).

Da mesma maneira, o valor "igualdade" apareceu como elemento central nas retóricas dos dois grupos. Para os favoráveis, as cotas promoviam a igualdade; para os contrários, elas ameaçavam a igualdade. Trata-se, obviamente, de usos do 
mesmo termo em sentidos diferentes. Podemos supor que para os favoráveis a igualdade está semanticamente próxima da ideia de equidade (Rawls, 1992) ou da igualdade substantiva (Feres Júnior; Zoninsein, 2008), significando algo como uma meta a ser atingida, uma igualdade que tem como pressuposto o combate à desigualdade entre os grupos, para que esses estejam efetivamente em posições iguais antes do "tiro de partida" nas corridas meritocráticas.

No outro caso, da retórica contrária, a igualdade é algo mais formal, como algo dado, próxima da ideia de mérito individual, que legitima as corridas por supor que todos saem da mesma linha de partida e em condições iguais. Em outros estudos, temos demonstrado que a mera saliência dessa igualdade formal se associa com a manutenção do preconceito implícito contra os negros e que a saliência da igualdade substancial anula esse preconceito (Lima et al., 2006).

Notamos que as retóricas se referem ainda à tese do class-over-race, que se tornou emblemática na compreensão do racismo. Os contrários às cotas afirmaram que o problema é de classe e não de cor ou, noutros termos mas no mesmo sentido, que a solução seria investir em escolas públicas. Visão que retoma as teses de Gilberto Freyre sobre a democracia racial brasileira. Dados semelhantes foram encontrados por Oliveira Filho (2009). Todavia, larga evidência demonstra que o avanço econômico não tem reduzido o racismo no Brasil (e.g. Andrews, 1991; Hasenbalg, 1985; Lovell, 1994; Santos, 2000). Além disso, outros estudos verificam que a cor da pele é uma poderosa variável mediadora na relação entre classe e racismo no Brasil, ou seja, quanto mais pobre e negro, mais racismo (Lima; Vala, 2004, 2005).

Apareceu ainda com destaque nos argumentos contrários às cotas a ideia de que "elas ferem a lógica do mérito". Trata-se de um argumento clássico nas sociedades individualistas. Jock Young (2003) descreve a meritocracia moderna como uma arena de corridas na qual existem três esferas: uma primeira pista na qual competem os melhores competidores e pelos melhores prêmios; mais abaixo, uma outra pista, em que disputam os de segundo escalão por prêmios menores. Numa terceira esfera, estariam os espectadores, separados dos competidores por um cordão sanitário (policial), sem competir, sem receber, mas vibrando com os prêmios em disputa. De modo que, meritocracia sem igualdade de oportunidades é uma corrida viciada, uma farsa, com pistas e prêmios específicos para competidores de determinadas categorias.

Finalmente, cabe referir que $16 \%$ dos favoráveis às cotas não justificaram sua posição. Esse fato parece indicar que tal atitude carece de fundamentação e pode ter uma base mais emocional que racional, sendo mais susceptível a mudanças. No caso dos contrários, apenas $0,3 \%$ não sabia, ou pelo menos não nos disse por que era contrário. 
Tabela 2 - Justificativas para as atitudes perante as cotas para estudantes pretos e pardos nas universidades públicas (2005) (dados em percentagens)

\begin{tabular}{|c|c|c|c|}
\hline Favoráveis & $\%$ & Contrários & $\%$ \\
\hline Promovem justiça social & 26,3 & Aumentam o preconceito & 20,6 \\
\hline Promovem a igualdade de oportunidades & 21,1 & $\begin{array}{l}\text { A solução seria investir } \\
\text { nas escolas públicas }\end{array}$ & 17,2 \\
\hline Medida emergencial & 18,4 & Ferem a lógica do mérito & 16,9 \\
\hline Criam possibilidade de ascensão social & 10,5 & $\begin{array}{l}\text { Medida discriminatória (a cor } \\
\text { não define a capacidade) }\end{array}$ & 13 \\
\hline Combatem o preconceito & 5,3 & Ferem o princípio de igualdade & 12,7 \\
\hline Permitem inclusão social & 2,6 & Problema é de classe e não de cor & 6,2 \\
\hline \multirow[t]{4}{*}{ Não justificaram } & \multirow[t]{4}{*}{15,8} & Trazem perda na qualidade do ensino & 3,7 \\
\hline & & \begin{tabular}{|l|}
$\begin{array}{l}\text { Existe dificuldade de } \\
\text { classificar a cor no Brasil }\end{array}$ \\
\end{tabular} & 2 \\
\hline & & $\begin{array}{l}\text { Outras (não são necessárias, } \\
\text { melhorar a estrutura do país, } \\
\text { oportunismo, demagogia, aumentar } \\
\text { vagas nas universidades etc.) }\end{array}$ & 7,4 \\
\hline & & Não justificaram & 0,3 \\
\hline Total & 100 & Total & 100 \\
\hline
\end{tabular}

Fonte: Banco de dados da pesquisa.

Elaboração dos autores.

Todavia, este primeiro estudo foi realizado quando as cotas ainda não estavam implantadas e, portanto, não havia contato entre cotistas e não cotistas. Será que o contato com os cotistas e mesmo a habituação com uma nova norma alteraram as atitudes dos estudantes desses cursos? Passados cinco anos, em 2010, as cotas foram implantadas na UFS. ${ }^{2}$ Foi nesse contexto que realizamos o segundo estudo.

\section{ESTUDO 2: ATITUDES PERANTE AS COTAS NA SUA IMPLANTAÇÃO}

Neste estudo analisamos as atitudes em relação às cotas dos estudantes de seis dos cursos mais concorridos, a fim de investigarmos se houve mudanças ao longo dos cinco anos pelo contato com os cotistas. A coleta de dados foi feita apenas com alunos do primeiro período e em turmas nas quais havia cotistas e não cotistas durante o segundo mês de aula.

\section{MÉTODO}

Ao todo, 214 estudantes colaboraram. Como nosso objetivo era analisar as atitudes perante as cotas no primeiro momento de sua implantação e o impacto do

2 Ficou estabelecido que 50\% das vagas seriam destinadas a estudantes de escolas públicas e, desse percentual, $70 \%$ seriam reservadas aos que se autodeclarassem pretos, pardos ou indígenas, e uma vaga por curso aos portadores de necessidades especiais. 
contato com os cotistas nessas atitudes, foi necessário excluir 26 casos das análises, por se tratarem de alunos de outros cursos, alunos que não cursavam o primeiro semestre ou por terem deixado boa parte das questões sem resposta e mais 74 $(34,6 \%)$ porque eram cotistas.

\section{Participantes}

O número de participante foi de 114: 23,7\% de medicina, 21,9\% de direito, $15,8 \%$ de psicologia, $14 \%$ de enfermagem e 8,8\% de odontologia. Neste estudo, aproveitando a criação recente do curso de fonoaudiologia e sua elevada concorrência no vestibular, pesquisamos também 18 estudantes ali inseridos (15,8\%). Em relação ao sexo, 65,5\% eram de sexo feminino. A idade variava de 16 a 45 anos $(M=19,23 ; D P=$ 3,56). A renda familiar de 44,6\% era superior a dez salários mínimos. Em relação à cor da pele autodeclarada, encontramos $11,1 \%$ que se autodefiniram como pretos, 43,4\% como pardos, $31,3 \%$ como brancos, $3 \%$ como amarelos e $1 \%$ como indígenas. Os restantes, 10,2\%, não escolheram uma dessas cores para se autodefinirem.

\section{Procedimentos e instrumentos}

Todos os procedimentos foram iguais aos do primeiro estudo. Apenas procedemos ao acréscimo no questionário de itens para avaliar o contato dos não cotistas com os cotistas. A questão utilizada instava que eles estimassem, em termos percentuais, a quantidade de pessoas negras na sua família, seus colegas de escola, colegas de universidade, sergipanos e brasileiros. A escala utilizada variou de 0 a 100\%. Para as análises estatísticas inferenciais, esses valores foram recodificados como variando de 0 a 10 .

\section{Resultados e discussão}

Novamente analisamos as percepções de justiça social e a avaliação da situação socioeconômica dos negros. A Tabela 3 nos mostra que permaneceu a avaliação de que os negros estavam numa situação pior $\left(M_{\text {geral }}=3,85\right)$; e novamente sem efeito significativo da cor da pele dos participantes $F(2,81)=1,14, p>.10$. Igualmente, essa situação permaneceu sendo considerada injusta $\left(M_{\text {geral }}=3,04\right)$, mas agora sem o efeito da cor da pele $F(2,81)<1$, n.s.

Tabela 3 - Médias e desvios padrões da percepção de justiça social em virtude da cor da pele (2010)

\begin{tabular}{l|r|r|r|r}
\hline \multicolumn{1}{c|}{ Percepção de justiça social } & Brancos & Pardos & Pretos & Total \\
\hline Como avalia a situação econômica dos negros & 3,75 & 3,91 & 3,91 & 3,85 \\
no Brasil em relação aos brancos?* & $(0,44)^{* * *}$ & $(0,48)$ & $(0,30)$ & $(0,45)$ \\
\hline Você acabou de avaliar a situação dos negros em relação & 3,07 & 2,98 & 3,18 & 3,04 \\
aos brancos. Como avalia a justiça dessa situação?** & $(0,78)$ & $(0,72)$ & $(0,87)$ & $(0,76)$ \\
\hline
\end{tabular}

Fonte: Banco de dados da pesquisa.

Elaboração dos autores.

* A escala variava de: 1 (muito melhor), 2 (melhor), 3 (igual), 4 (pior) e 5 (muito pior).

* A escala variava de: 1 (totalmente justa), 2 (justa), 3 (injusta) e 4 (totalmente injusta).

*** Entre parênteses consta o desvio padrão. 
Contudo, quando comparamos os dados do Estudo 1 com os do Estudo 2, chama a atenção a enorme discrepância entre as avaliações da situação dos negros e a percepção de justiça. No primeiro estudo, feito antes da entrada dos negros nos cursos mais concorridos via cotas, a média geral de percepção de que os negros estavam em pior situação que os brancos era de 4,25 numa escala de cinco pontos; média esta significativamente superior aos 3,85 do presente estudo, $t(107)=3,70$, $p<.001$. Também a média geral da percepção de injustiça deste estudo $(3,04)$ foi ligeiramente inferior à encontrada no Estudo $1(3,39), t(100)=-1,87, p=.06 . \mathrm{Ou}$ seja, a entrada dos cotistas pareceu ter diminuído a percepção dos estudantes sobre a exclusão econômica e a injustiça da situação dos negros.

Analisamos em seguida as atitudes perante as cotas, considerando como variável moderadora a cor da pele dos estudantes. Assim como no primeiro estudo, agregamos os pretos com os pardos para formar a categoria "negros". Os estudantes, em sua maioria, mostraram-se contrários às cotas sociais. Entre os pesquisados, $54,1 \%$ foram contrários, $30,6 \%$ favoráveis e os restantes, $15,3 \%$, não se posicionaram. Novamente não houve efeito da cor da pele nessas atitudes, $X^{2}(2, \mathrm{n}=85)<1$, n.s (Figura 2).

No entanto, quando comparamos as atitudes dos estudantes perante as cotas sociais em 2005 e em 2010, observamos uma diferença ligeiramente significativa, $X^{2}(2, \mathrm{n}=334)=5,95, p=.07$. A análise dos residuais ajustados indica que a condição crítica para a diferença entre os dois grupos é célula dos contrários às cotas sociais, em 2005 eram 67,4\%, em 2010 esse percentual caiu para 54,1\%.

Muito mais contrários ainda que no primeiro estudo mostraram-se os estudantes quando indagados sobre suas atitudes em relação às cotas raciais em 2010. Nenhum dos pesquisados foi favorável, $94 \%$ foram contrários e $6 \%$ não se posicionaram. Esse dado, assim como ocorrera no primeiro estudo, não foi afetado pela cor da pele dos respondentes, $X^{2}(1, \mathrm{n}=84)=1.22, p>.10($ Figura 2$)$.

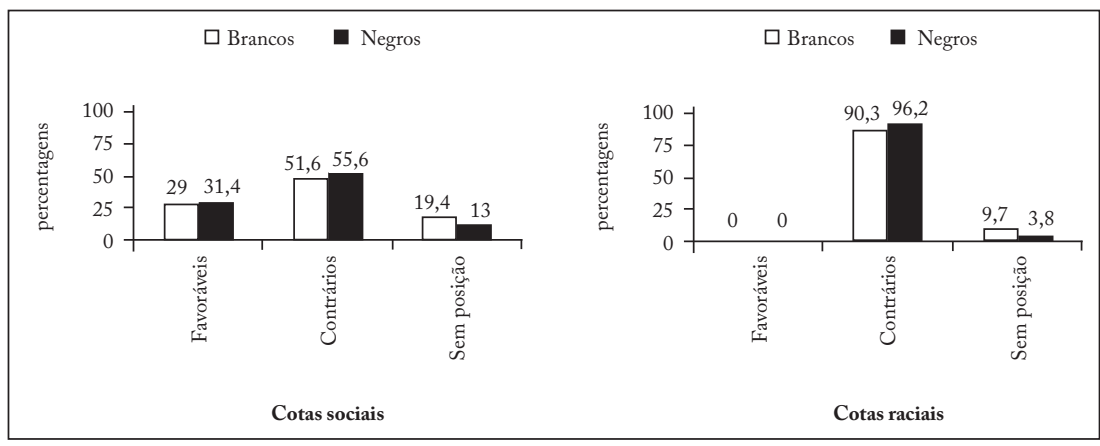

Figura 2 - Atitudes perante as cotas raciais e sociais nas universidades públicas em virtude da cor de pele dos participantes (2010) (dados em percentagens).

Fonte: Banco de dados da pesquisa.

Elaboração dos autores. 
Novamente há diferenças significativas quando comparamos as respostas em 2005 com as respostas em 2010, $X^{2}(2, \mathrm{n}=329)=11,29, p<.01$. A análise dos residuais indica que a condição de resposta que define essas diferenças está na célula dos favoráveis às cotas raciais, que eram 9,8\% em 2005 e nenhum (0\%) em 2010.

Analisamos também neste estudo os argumentos que justificavam as atitudes em relação às cotas raciais. Como não havia estudantes favoráveis e as justificativas para o não posicionamento não interessavam aos objetivos deste trabalho, apresentamos na Tabela 4 apenas as justificativas dos que foram contrários às cotas raciais (94\% dos entrevistados). Podemos observar que os argumentos para justificar a posição contrária às cotas não mudaram de 2005 para 2010, apenas o peso de cada um deles variou nesse período.

Em 2005, antes de as cotas estarem implantadas, o argumento mais usado contra elas era o de que aumentariam o preconceito contra os negros. Em 2010, depois de implantadas, a maior preocupação era com o caráter discriminatório das cotas, evidentemente contra os não negros. Em 2005 havia mais preocupação com o investimento em escolas públicas para resolver o problema (17,2\% das respostas fizeram essa referência); em 2010, apenas 3,3\% se referiram a esse aspecto.

Tornou-se mais relevante então a tese do class-over-race - "o problema é de classe e não de cor" -, que se constituiu num mito legitimador poderoso do racismo brasileiro. Também perderam força os argumentos que afirmavam que as cotas feriam as lógicas do mérito e da igualdade. A questão central que estruturou a posição contrária de mais de dois terços dos estudantes em relação às cotas raciais depois de elas estarem implantadas apareceu marcada pela afirmativa de elas serem sentidas como discriminatórias. Evidentemente, as ideias de mérito individual e de igualdade formal são a base ideológica desse argumento, mas nele a preocupação central é a discriminação, ou a sensação de ameaça de perda de privilégio de um grupo pela ascensão do outro, como refere Blumer (1958).

Também merece destaque o fato de que, em 2005 , apenas $0,3 \%$ não justificou a oposição às cotas, enquanto em 2010 esse valor sobiu para quase $12 \%$. Isso parece querer significar que alguns argumentos perderam força depois de implantadas as políticas de acesso. Um deles foi o de que as cotas aumentavam o preconceito contra os negros, que era o mais importante antes da implantação e perdeu 8\% das respostas, caindo para o segundo posto depois da implantação do sistema.

Tabela 4 - Justificativas para as atitudes perante as cotas de acesso para estudantes pretos e pardos nas universidades públicas (2010) (dados em percentagens)

\begin{tabular}{l|c|l}
\hline \multicolumn{1}{c|}{ Categoria } & $\%$ & \multicolumn{1}{c}{ Exemplos de respostas } \\
\hline $\begin{array}{l}\text { São discriminatórias (a cor/raça } \\
\text { não define a capacidade) }\end{array}$ & 39,8 & "A cor da pele não indica sua capacidade" \\
\hline Aumentam o preconceito e a discriminação & 12,5 & $\begin{array}{l}\text { "Pois isso, por si só, já é uma forma de } \\
\text { discriminação e distinção entre etnias" }\end{array}$ \\
\hline Problema é de classe e não de cor & 12,5 & $\begin{array}{l}\text { "Porque o que deve ser analisado é } \\
\text { a condição social e não a etnia" }\end{array}$ \\
\hline
\end{tabular}


(...continuação)

\begin{tabular}{|c|c|c|}
\hline Categoria & $\%$ & Exemplos de respostas \\
\hline Ferem o princípio de igualdade & 4,5 & $\begin{array}{l}\text { "Todos devem ser encarados como } \\
\text { iguais. As oportunidades devem ser as } \\
\text { mesmas, só assim se fará justiça" }\end{array}$ \\
\hline Existe dificuldade de classificar a cor no Brasil & 4,5 & $\begin{array}{l}\text { "Porque acho que o critério de cor não é viável" } \\
\text { "Não há um justo método de } \\
\text { classificar a cor dos brasileiros" }\end{array}$ \\
\hline A solução é investir nas escolas públicas & 3,3 & $\begin{array}{l}\text { "Não atingem a raíz do problema: } \\
\text { educação primária e fundamental" }\end{array}$ \\
\hline Outras & 11,1 & $\begin{array}{l}\text { "Não há sentido" } \\
\text { "Não me interesso" }\end{array}$ \\
\hline Não justificaram & 11,8 & \\
\hline Total & 100 & \\
\hline
\end{tabular}

Fonte: Banco de dados da pesquisa.

Elaboração dos autores.

Neste estudo, analisamos o grau de contato intergrupal dos estudantes. Para tanto, perguntamos sobre percentagens de pessoas negras com quem os participantes mantinham relações de situação de intimidade crescente. Eles deveriam estimar o percentual de pessoas de pele negra nos seguintes grupos: parentes, amigos, estudantes da universidade, estudantes da escola de ensino médio, sergipanos e brasileiros. Os resultados indicaram que, embora $11 \%$ tenham se autodeclarado pretos e $43 \%$ pardos, pouco mais de $21 \%$ afirmaram ter parentes de cor negra. Também foi notada alguma percepção de segregação dos espaços sociais nesses dados; ainda que os estudantes estimassem mais de $50 \%$ dos brasileiros e de $45 \%$ dos sergipanos como sendo negros, suas escolas eram mais "brancas" (apenas 25\% de negros), sua universidade também, assim como seus amigos (Figura 3).

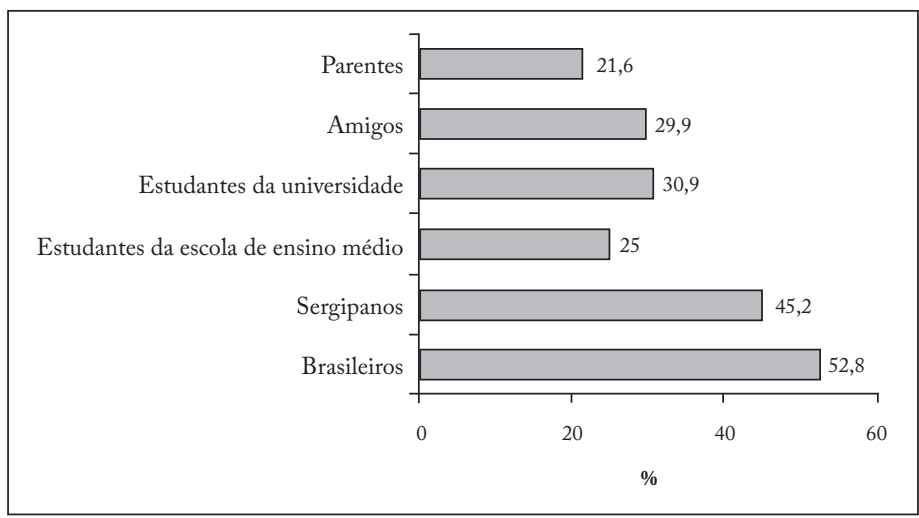

Figura 3 - Percentuais médios de pessoas negras que os participantes estimaram existir em sua familia, entre seus colegas de escola e universidade, entre os sergipanos e brasileiros (a escala variava de 0 a $100 \%$ ).

Fonte: Banco de dados da pesquisa.

Elaboração dos autores. 
Quando analisamos o efeito da cor da pele dos participantes no grau de contato com os negros, encontramos apenas dois efeitos marginalmente significativos. Os participantes negros afirmaram existir mais negros na sua família $(M=2,60 ; D P$ $=2,17)$ que os participantes brancos $(M=1,70 ; D P=1,88), F(1,82)=2,40, p=.06$. Em contrapartida, para os participantes brancos a universidade estava mais povoada por estudantes negros $(M=3,55 ; D P=1,26)$ do que avaliaram os participantes negros $(M=2,91 ; D P=1,60), F(1,83)=3,64, p=.06 .^{3}$

Chama a atenção o fato de os participantes negros estimarem que apenas $26 \%$ de seus parentes eram negros. Esse dado provavelmente sofre o impacto do tipo de representação social da cor que cada grupo social constrói. Nossa categorização do grupo "negros" foi motivada por considerações teóricas sobre a importância política das classificações bipolares (e.g., pretos/brancos) para combater a ideologia da mestiçagem e suas relações com o ideário do branqueamento (ver Munanga, 1999, para uma discussão) e também pelos critérios do IBGE, ${ }^{4}$ que sugerem a junção dos pretos $(11,1 \%$ da nossa amostra se autodefiniram assim) com os pardos $(43,4 \%)$. De forma que temos mais de $50 \%$ dos pesquisados classificados como negros. Muitos deles, no entanto, não se viam assim, uma vez que afirmaram que apenas $26 \%$ de seus parentes eram negros. $\mathrm{E}$, nesse caso, não se trata de um problema da classificação adotada pelo IBGE, como alguns pesquisadores do racismo propõem (e.g., Fry et al., 2007).

Com efeito, se fizermos a mesma análise utilizando as três categorias de autodefinição de cor (pretos, pardos e negros), o efeito da cor sobre a percepção de parentes negros desaparece, $F(2,82)=2,04, p=.13$. Os estudantes que se autodefiniram como "pretos" $(11,1 \%)$ estimaram que apenas $30 \%$ de seus parentes eram negros, e os pardos $(43,4 \%)$ afirmaram que $25 \%$ dos seus familiares eram negros. Ou seja, os quase $28 \%$ de participantes que se classificaram como negros (pretos ou pardos), mas que afirmaram não ter parentes negros, estão muito provavelmente fazendo o branqueamento de sua família.

Como refere Piza (2000), no Brasil a percepção da cor é um fenômeno complexo que considera os traços físicos, como a cor e o tipo de cabelo, a cor da pele e os traços faciais do indivíduo, numa relação de comparação social com um interlocutor de mesma cor - pois o que predomina aqui é a regra da aparência por oposição à "regra de origem" dos Estados Unidos. Podemos então pensar que os participantes que se viam como pardos talvez possuam alguma teoria naive sobre a cor da pele na qual a colaboração da cor preta para composição dessa categoria é mínima. Ou seja, estão capturados pela ideologia do branqueamento, como tem sido observado em vários outros estudos com adultos brasileiros (Lima; Vala, 2004, 2005; Turra; Venturi, 1995) e com crianças (França; Monteiro, 2002; França; Lima, 2011).

3 A escala variava de $0(0 \%)$ a 10 (100\% de contato).

4 Que incorporou, nesse sentido, uma antiga reinvindicação de parte dos movimentos negros de considerar todos os descendentes de africanos, independentemente da mestiçagem, como negros. 
Também merece destaque que estudantes que conviviam ao mesmo tempo na instituição - e, por serem dos mesmos cursos, geralmente frequentando os mesmos espaços - tiveram percepções distintas sobre a quantidade de negros na universidade. Para os brancos existiam mais negros na universidade que para os negros. Trata-se aqui de percepções subjetivas ou de processos de construção da realidade social que trazem em si as âncoras dos interesses grupais e que podem, num dos casos, traduzir-se na frase: "já tem demais aqui". Existe na literatura evidência empírica para um fenômeno chamado "efeito da superexclusão" (overexclusion effect) (Leyens; Yzerbit, 1992), o qual indica que membros de grupos dominantes, quando em dúvida sobre se incluem alguém ou não em seu grupo, geralmente optam por não incluir. Como refere Brewer (2000), a necessidade de exclusividade está associada com altos níveis de conservadorismo e de resistência à mudança.

Quando analisamos o efeito do contato com os negros nas atitudes em relação às cotas raciais, não encontramos nenhuma relação significativa, $F(1,111) \leq$ 1 , n.s. Esse dado pode ser mais bem entendido quando observamos os argumentos contrários às cotas ouvidos na época. Neles era candente a ideia de injustiça, tornada emblemática pela mídia de Sergipe logo depois do resultado do vestibular, quando publicou vários artigos denunciando situações de estudantes de escolas privadas que obtiveram pontuações maiores que outros de escolas públicas para determinados cursos, com destaque para medicina, e ainda assim "perderam" a vaga para estes.

Como na época afirmou M.W., uma das estudantes que se sentiu prejudicada: "As cotas tiram o direito dos estudantes das escolas particulares, acho uma injustiça, muitos alunos cotistas serão discriminados na universidade pelos próprios alunos que vão achar que eles são 'menores". ${ }^{5}$ Além disso, é importante lembrar que esse estudo analisou as atitudes dos estudantes durante o segundo mês de aula, de tal forma que o contato entre cotistas e não cotistas ainda estava em fase inicial.

Com efeito, quando foi feita a seguinte questão: "Alguns estudantes não aprovados no último vestibular na UFS obtiveram pontuação mais alta que alguns cotistas aprovados. O que você acha dessa situação?", numa escala que variava de 1 (totalmente justa) a 4 (totalmente injusta), observamos que as respostas foram influenciadas pelas atitudes perante as cotas, $F(1,104)=3,95, p<.05$. Os contrários avaliaram essa situação como ainda mais injusta $(M=3,49 ; D P=0,77)$ que os sem posição definida $(M=3,0 ; D P=0,77)$.

Se acrescentarmos a esse dado aquele que apareceu como argumento central nas justificativas contra as cotas, i.e., de que elas eram uma medida discriminatória, conseguimos ter um bom veio interpretativo para a radicalização das atitudes contrárias às cotas raciais nos cursos mais concorridos da UFS depois de sua implantação. Trata-se dos estertores de um grupo que percebe seu poder ameaçado, que sente que suas posições antes garantidas agora são menos acessíveis e que reage a isso recrudescendo seu antagonismo contra aquilo que o ameaça.

5 Disponível em: <http://www.infonet.com.br/educacao/ler.asp?id=94544>. Acesso em: abr. 2010. 


\section{DISCUSSÃO GERAL}

O objetivo desta pesquisa foi analisar as atitudes perante as cotas raciais e sociais de estudantes universitários de Sergipe em dois momentos: antes e depois de sua implantação. Os pressupostos teóricos fundamentais do estudo decorreram das teses de Blumer (1958) sobre a ameaça à posição de dominação dos grupos, de Jackman (1994), sobre o paternalismo nas relações de dominação, e de Allport (1954/1979), sobre os impactos do contato nas relações intergrupos. Procuramos integrar essas teorias para investigar a hipótese de que a implantação de cotas recrudesce as atitudes contrárias a elas, mas que o contato com os cotistas negros pode atuar como um catalisador na produção de atitudes mais favoráveis.

Os resultados encontrados indicaram que, ainda que considerassem desigual e injusta a situação econômica dos negros comparativamente aos brancos no Brasil, os estudantes se mostraram em sua maioria contrários às cotas sociais e, sobretudo, às cotas raciais. Todavia, enquanto a oposição às cotas sociais decresceu com a sua implantação - em 2005 eram 67\% e em 2010 foram 54,1\% -, cresceu a oposição às cotas raciais $-9,8 \%$ eram favoráveis antes de implantadas, $0 \%$ depois da implantação. Esses resultados parecem significar pelo menos duas questões importantes.

Primeiro, confirmam-se os pressupostos do paternalismo de Jackman (1994) quando propõe que uma das dimensões do preconceito paternalista é a de publicamente referir como injusta e inadmissível a dominação e sofrimento das minorias, mas, em contrapartida, ser contrário a políticas que proponham mudanças sociais, ou seja, agem como maus "pais", que dizem amar seus "filhos" mas não querem que eles cresçam e assim saiam de debaixo das asas do seu domínio. Cabe lembrar que os que mais consideraram injusta a situação dos negros foram os brancos e pardos.

Segundo, os resultados encontrados foram contrários à nossa hipótese sobre o efeito do contato nas atitudes perante as cotas. Contudo, dois aspectos devem ser destacados antes de descartarmos os efeitos benéficos do contato intergrupal. Como vimos, para Allport, uma das condições de efetividade dos contatos na redução dos preconceitos é a de que se desenvolvam atividades de cooperação com objetivos comuns entre os grupos. Pettigrew (2007) desenvolve essa ideia quando mostra que é o surgimento de amizade com pessoas de grupos ou categorias diferentes que reduz as visões negativas do outro. Infelizmente, o ambiente acadêmico e sua lógica meritocrática estrita, presente sobretudo nos cursos mais concorridos, não são ainda o lugar ideal para a criação de atividades de cooperação nas quais os grupos interajam visando a objetivos comuns. Pensamos ser essa uma tarefa pedagógica a ser estimulada nos conselhos e departamentos universitários, a fim de permitir que efetivamente se possa combater, além da desigualdade de acesso, os estereótipos e preconceitos sociais.

Nossos dados demonstram que o contato entre cotistas e não cotistas era mínimo, embora estudassem nas mesmas salas - ainda que 11\% dos não cotistas tenham se autodefinido como pretos e $43 \%$ como pardos, e ainda que tenhamos nas turmas pesquisadas $34,6 \%$ de cotistas ( $70 \%$ destes como cotistas raciais) -, 
apenas 29\% dos amigos dos estudantes pesquisados eram negros. Outro aspecto a ser considerado é que o segundo estudo foi realizado nos dois primeiros meses de contato entre cotistas e não cotistas, quando "as injustiças do vestibular" ainda estavam efervescentes. Em novas investigações, acompanharemos se o contato com os cotistas ao longo do curso torna mais favorável as atitudes perante as cotas.

Observamos ainda, na comparação dos dois estudos, que os argumentos que justificam as posições perante as cotas mudam seu peso ou ordem de importância, mas mantêm seu conteúdo. De maneira geral, as mudanças no peso relativo de cada argumento contrário às cotas, em virtude de elas deixarem de ser uma promessa e terem se tornando um fato, podem ser interpretadas à luz da teoria do senso de posição grupal de Blumer (1958). Como vimos, de acordo com essa teoria, o grupo dominante está preocupado com sua posição de dominação, em que cada um esteja no seu lugar, e, para isso, como referiu Jackman (1994), usa de refinamento ideológico e trata os dominados como um pai trata os filhos, preocupando-se com eles e amando-os, desde que e para que eles não abandonem seus postos de submissão.

Com efeito, em 2005, quando os cotistas negros ainda estavam fora da academia, os estudantes dos cursos mais elitizados da UFS argumentavam contra as cotas dizendo que elas trariam malefícios aos próprios negros, que sofreriam preconceito. Então, dessa maneira, supostamente estavam protegendo essa categoria do estigma, “ajudando-a", para usar a expressão clássica de Jackman (1994), empregando a doce persuasão das formas paternalistas de dominação. Todavia, em 2010 eles "invadem" a universidade e assim ameaçam a posição do grupo dominante, seu território e espaço, antes quase exclusivos. A ameaça à posição de dominação do grupo, como refere Blumer (1958), faz surgir outra retórica; agora a preocupação não é mais com o sofrimento que os dominados terão se deixarem de ser dominados, mas com a perda de poder e espaço que as "cotas discriminatórias" trouxeram ao grupo antes confortavelmente instalado nas posições de poder.

As análises nos conduzem a pensar que, independentemente de resolverem ou não a flagrante desigualdade entre brancos e negros no nosso país, as políticas de ação afirmativa, com destaque para as cotas raciais, estimulam o debate sobre raça, racialização, justiça e racismo numa sociedade que sempre pareceu dormir no berço esplêndido do mito da democracia racial. Se as cotas são "certas" ou "erradas", "justas" ou "injustas", é um tema de profundos debates e polêmicas. Para nós, no entanto, não restam dúvidas de que elas têm permitido um enorme avanço no interesse e produção de reflexões sobre o racismo no Brasil. E têm trazido à luz da crítica antigos mitos legitimadores das assimetrias de poder entre brancos e negros, a exemplo da ideia de preconceito de classe e não de cor.

Nosso estudo apresenta algumas limitações dignas de nota. Às vezes chamamos de preconceito o fato de ser contrário às cotas. Sabemos que não existe relação direta entre a atitude perante as cotas para negros e o preconceito racial (Silva, 2007) e, evidentemente, consideramos que muitos dos contrários discordam apenas dos meios e não dos fins. De modo que, muito provavelmente, trata-se mais 
de preocupação com a posição do próprio grupo e de seus privilégios do que de preconceito contra o outro.

Contudo, nossos pressupostos teóricos nos conduzem a afirmar que existe também uma relação muito forte entre ser contra as políticas propositivas de igualdade e o preconceito (Jackman, 1994). De fato, a análise dos argumentos dos participantes indicou importante mudança de um foco na proteção dos interesses do outro grupo, que é percebido como minoritário (antes das cotas), para a proteção dos interesses do endogrupo discriminado (depois das cotas).

Em futuras investigações acrescentaremos aos indicadores de atitudes perante as cotas os indicadores de preconceito racial implícito e explícito, para analisarmos suas relações. Além disso, a ideia de que a entrada dos cotistas ameaça o senso de posição grupal dos não cotistas foi nestes estudos uma suposição interpretativa que merece maior destaque empírico, inclusive utilizando indicadores de ameaça real e simbólica que a literatura psicossocial tem adotado (e.g., Stephan; Diaz-Loving; Duran, 2000).

\section{REFERÊNCIAS}

AlLPoRT, Gordon Willard. The nature of prejudice. 3. ed. Wokingham: Addison-Wesley, 1954/1979.

Andrews, George Reid. Negros e brancos em São Paulo (1888-1988). Bauru: EDUSC, 1991.

BARdin, Laurence. Análise de conteúdo. Edições 70: Lisboa, 1979.

Billig, Michael.Argumentando e pensando: uma abordagem retórica à psicologia social. Petrópolis: Vozes, 2008.

; Condor, Susan; Edwards, Derek; Gane, Mike; Middleton, David; Radley, Alan. Ideological dilemmas: a social psychology of everyday thinking. Londres: Sage Publications, 1988.

Bittar, Mariluce; Almeida, Carina Elisabeth Maciel de. Mitos e controvérsias sobre a política de cotas para negros na educação superior. Revista Educar, Coritiba: Editora da UFPR, n. 28, p. 141-159, 2006.

Blumer, Herbert. Race prejudice as a sense of group position. The Pacific Sociological Review, Califórnia: UCLA Press, v. 1, n. 1, p. 3-7, 1958.

Вово, Lawrence; Hutchings, Vincent L. Perceptions of racial group competition: Extending Blumer's theory of group position to a multiracial social context. American Sociological Review, [s.1.]: Sage, v. 61, p. 951-972, 1996.

Brandão, Carlos da Fonseca. As cotas na universidade pública brasileira: será esse o caminho? Campinas: Autores Associados, 2005. (coleção Polêmicas do Nosso Tempo, v. 92). 
Brandão, André Augusto; Marins, Mani Tebet Azevedo de. Cotas para negros no ensino superior e formas de classificação racial. Educação e Pesquisa, São Paulo: FEUSP, v. 33, n. 1, p. 27-45, jan./abr. 2007.

Brasil. Ministério da Saúde. Conselho Nacional de Saúde. Resolução n. 196, de 10 de outubro de 1996. Aprova as diretrizes e normas regulamentadoras de pesquisas envolvendo seres humanos. Diário Oficial da União, Brasília, DF, 16 out. 1996.

Brewer, Marilynn B. Reducing prejudice through cross-categorization: effects of multiple social identities. In: Osкамp, Stuart (Ed.). Reducing prejudice and discrimination. Londres: Lawrence Erlbaum, 2000.

Crosby, Faye J.; Iyer, Aarti; Sincharoen, Sirinda. Understanding affirmative action. Annual Review of Psychology, Palo Alto, CA/USA: [s.n.], v. 57, p. 585-611, 2006.

Feres Júnior, João; Zoninsein, Jonas. A consolidação da ação afirmativa no ensino superior brasileiro. In: Zoninsein, Jonas; Feres Júnior, João (Orgs.). Ação afirmativa no ensino superior brasileiro. Belo Horizonte: Editora da UFMG, 2008. p. 9-34.

França, Dalila Xavier de; Lima, Marcus Eugênio Oliveira. Affirmative action policies and ethnic identity in black and indigenous children of Brazil. International Journal of Conflict and Violence, [s.1: s.n.], v. 5, n. 1, p. 200-210, 2011.

; Monteiro, Maria Benedicta. Identidade racial e preferência em crianças brasileiras de cinco a dez anos. Psicologia, Lisboa: APP, v. XVI, n. 4, p. 293-323, 2002.

Fry, Peter Henry; Monteiro, Simone; Maio, Marcos Chor, Bastos, Francisco Inácio; SANTos, Ricardo Ventura. AIDS tem cor ou raça? Interpretação de dados e formulação de políticas de saúde no Brasil. Cadernos de Saúde Pública, Rio de Janeiro: Fiocruz, v. 23, n. 3, p. 497-523, mar. 2007.

FreYre, Gilberto. Casa-grande e senzala: formação da família brasileira sob o regime de economia patriarcal. Lisboa: Edição Livros do Brasil, 1933/1983.

Glick, Peter; Rudman, Laurie. Sexism. In: Dovidio, John F.; Hewstone, Miles; Glick, Peter; Esses, Victoria (Eds.). The sage handbook of prejudice, stereotyping and discrimination. Nova Delhi: Sage, 2010. p. 328-244.

Gomes, Joaquim Benedito Barbosa. O debate constitucional sobre as ações afirmativas. In: Santos, Renato Emerson dos; Lobato, Fátima (Orgs.). Ações afirmativas: políticas públicas contras desigualdades raciais. Rio de Janeiro: DP \&A Editora, 2003.p. 15-57.

Hasenbalg, Carlos. Race and socioeconomic inequalities in Brazil. In: Fontaine, Pierre-Michel (Ed.). Race, class and power in Brazil. Centre for Afro-American Studies, University of California: Los Angeles, 1985. p. 25-41.

Jackman, Mary. The velvet glove. Berkeley: University of California Press, 1994.

Jost, John T.; Banaji, Mahzarin. The role of stereotyping in system-justification and the production of false consciousness. British Journal of Social Psychology, Londres: Wiley-Blackwell, v. 33, p. 1-27, 1994. 
LPP/UERJ - Laboratório de Políticas Públicvas da UERJ.2009. Disponível em : <http:// www.lpp-buenosaires.net/lpp/programas_exibir.asp?tipo=2\&COD_PROGRAMA=8, oado>. Acesso em : 12 dez. 2009.

Leyens, Jacques Philippe; Yzerbyt, Vincent Y. The ingroup overexclusion effect: impact of valence and confirmation on stereotypical information search. European Journal of Social Psychology, Londres: EAESP, v. 22, p. 549-569, 1992.

Lima, Marcus Eugênio Oliveira. Preconceito. In:Torres, Ana Raquel Rosas; Camino, Leoncio; Lima, Marcus Eugênio Oliveira; Pereira, Marcos Emanoel (Orgs.). Psicologia social: temas e teorias. 1. ed. Brasília: Technopolitik, 2011. p. 451-500.

; VAla, Jorge. Sucesso social, branqueamento e racismo. Psicologia: teoria e pesquisa, v. 20, Brasília: UnB, n. 1, p. 11-19, jan./abr. 2004.

. A cor do sucesso: efeitos da performance social e econômica no branqueamento e na infra-humanização dos negros no Brasil. Psicologia USP, São Paulo: USP, v. 16, n. 3, p. 143-166, 2005.

; Machado, Caliandra; Ávila, Josele; Lima, Carolina; VAla, Jorge. Normas sociais e preconceito: o impacto da igualdade e da competição no preconceito automático contra os negros. Psicologia: reflexão e crítica, Porto Alegre: UFRGS, v. 19, p. 309-319, 2006.

Lovell, Peggy A. Race, gender, and development in Brazil. Latin American Research Review, Austin: University of Texas, v. 29, p. 7-35, 1994.

Maggie, Yvone. Políticas de cotas e o vestibular da UnB ou a marca que cria sociedades divididas. Horizontes Antropológicos, Porto Alegre: UFRGS, ano 11, n. 23, p. 286-291, jan./jun. 2005.

Munanga, Kabengele. Rediscutindo a mestiçagem: identidade nacional versus identidade negra. Petropólis: Vozes, 1999.

Moenlec ke, Sabrina. Ação afirmativa: história e debates no Brasil. Cadernos de Pesquisa, São Paulo: Fundação Carlos Chagas; Campinas: Autores Associados, n. 117, p. 197217, nov. 2002.

Nery, Maria da Penha; Costa, Liana Fortunato. Afetividade entre estudantes e sistema de cotas para negros. Paidéia, Ribeirão Preto: USP, v. 19, n. 43, p. 257-266, maio/ago. 2009.

Neves, Paulo Sérgio da Costa; Lima, Marcus Eugênio Oliveira. Percepções de justiça social e cotas para estudantes negros e pardos em universidades públicas: estudos de caso com universitários e pré-vestibulandos. Revista Brasileira de Educação, Rio de Janeiro: ANPEd; Campinas: Autores Associados, v. 12 n. 34, p. 17-38, jan./abr. 2007.

Oliveira Filho, Pedro de. A mobilização do discurso da democracia racial no combate às cotas para afrodescendentes. Estudos de Psicologia, Campinas: Núcleo de Editoração SBI, v. 26, p. 429-436, 2009. 
Piza, Edith. Branco no Brasil? Ninguém sabe, ninguém viu. In: Guimarães, Antônio Sérgio Alfredo; Huntley, Lynn Walker (Orgs.). Tirando a máscara: ensaios sobre racismo no Brasil. São Paulo: Paz e Terra, 2000. p. 97-126.

Pereira, Cícero Roberto; Vala, Jorge; Costa-Lopes, Rui. From prejudice to discrimination: the legitimizing role of perceived threat in discrimination against immigrants. European Journal of Social Psychology, Londres: EAESP, v. 40, p. 1.231-1.250, 2010.

Pettigrew, Thomas. Generalized intergroup contact effects on prejudice. Personality and Social Psychology Bulletin, [s.1.]: Sage, v. 23, p. 173-185, 2007.

; Tropp, Linda. A meta-analytic test of intergroup contact theory. Journal of Personality and Social Psychology, Califórnia: UCLA Press, v. 90, n. 5, p. 751$-783,2006$.

Queiroz, Delcele Mascarenhas; Santos, Jocélio Teles dos. Sistema de cotas: um debate. Dos dados à manutenção de privilégios e de poder. Educação E̊ Sociedade, Campinas: CEDES, v. 27, n. 96 especial, p. 717-737, out. 2006.

Quillian, Lincoln. New approaches to understandind racial prejudice and discrimination. Annual Review of Sociology, Palo Alto, USA: [s.n.], v. 32, p. 299-328, 2006.

RAwls, John. Justiça como equidade: uma concepção política, não metafísica. Lua Nova, São Paulo: CEDEC, n. 25, p. 25-59, 1992.

Rio de Janeiro (Estado). Lei n. 3.708, de 9 de novembro de 2001. Institui cota de até $40 \%$ (quarenta por cento) para as populações negra e parda no acesso à universidade do estado do Rio de Janeiro e à universidade estadual do norte fluminense, e dá outras providências. Diário Oficial (do Rio de Janeiro), Rio de Janeiro, 12 nov. 2001. Disponível em: <http://gov-rj.jusbrasil.com.br/legislacao/90840/lei-3708-01>. Acesso em: 10 out. 2011.

Santana, Elaine Barbosa. As políticas públicas de ação afirmativa na educação e sua compatibilidade com o princípio da isonomia: acesso às universidades por meio de cotas para afrodescendentes. Ensaio: avaliação e políticas públicas em educação, Rio de Janeiro: Cesgranrio, v. 18, n. 69, p. 736-760, out./dez. 2010.

SAntos, Hélio. Uma avaliação do combate às desigualdades raciais no Brasil. In: Guimarães, Antônio Sérgio Alfredo; Huntley, Lynn Walker (Orgs.). Tirando a máscara: ensaios sobre racismo no Brasil. São Paulo: Paz e Terra, 2000. p. 53-76.

Sidanius, Jim; Pratto, Felicia. Social dominance: an intergroup theory of social hierarchy and oppression. New York: Cambridge University Press, 1999.

Silva, Paula Bacellar e. Normas sociais e preconceito: o impacto da meritocracia e da igualdade no preconceito contra os cotistas em duas universidades públicas. Dissertação (Mestrado em Psicologia) - Faculdade de Psicologia, Universidade Federal da Bahia, Bahia, 2007. 
Stephan, Walter; Diaz-Loving, Rolando; Duran, Anne. Integrated threat theory and intercultural attitudes: Mexico and the United States. Journal of Cross-Cultural Psychology, [s.1.]: Sage, v. 31, n. 2, p. 240-249, mar. 2000.

Telles, Edward Eric. Race in another America: the significance of skin color in Brazil. Princeton and Oxford: Princeton University Press, 2006.

Turra, Cleusa; Venturi, Gustavo. Racismo cordial: a mais completa análise sobre preconceito de cor no Brasil. São Paulo: Ática, 1995.

Tyler, Tom. Psychological perspectives on legitimacy and legitimation. Annual Review of Psychology, Palo Alto, USA: [s.n.], v. 57, p. 375-400, 2006.

Vasconcelos, Simão Dias; Silva, Ednaldo Gomes da. Acesso à universidade pública através de cotas: uma reflexão a partir da percepção dos alunos de um pré-vestibular inclusivo. Ensaio: avaliação e políticas públicas em educação, Rio de Janeiro: Cesgranrio, v. 13, n. 49, p. 453-468, out./dez. 2005.

Weber, Max. Power, domination, and legitimacy. In: Olsen, Marvin Elliott; Marger, Martin N. (Eds.). Power in modern societies. San Francisco: Westview Press: 1947/1993. p. 37-47.

Winant, Howard. Race and race theory. Annual Review of Sociology, Palo Alto, USA: [s.n.], v. 26, n.1, p. 169-185, 2000.

Wood, Wendy. Attitude change: persuasion and social influence. Annual Review of Psychology, Palo Alto, USA: [s.n.], v. 51, p. 539-570, 2000.

Young, Jock. A sociedade excludente: exclusão social, criminalidade e diferença na modernidade recente. Rio de Janeiro: Revan, 2003.

\section{SOBRE OS AUTORES}

Marcus Eugênio Oliveira Lima é doutor em psicologia social pelo Instituto Superior de Ciências do Trabalho e da Empresa (ISCTE - Portugal). Professor da Universidade Federal de Sergipe (UFS).

E-mail:meolima@uol.com.br

Paulo Sérgio da Costa Neves é doutor em sociologia e ciências sociais pela Université Lumière Lyon 2 (França). Professor Universidade Federal de Sergipe (UFS).

E-mail:pneves@ufs.br

Paula Bacellar e Silva é doutoranda em psicologia pela Universidade Federal da Bahia (UFBA).

E-mail: polinhabacellar@gmail.com 
MARCUS EUGÊNIO OLIVEIRA LIMA, PAULO SÉRGIO DA COSTA NEVES E PAULA BACELLAR E SILVA

A implantação de cotas na universidade: paternalismo e ameaça à posição dos grupos dominantes

A fim de entender como se manifestam e desenvolvem as atitudes perante as cotas, realizamos dois estudos, um antes da implantação desse sistema e outro depois. Participaram 334 estudantes dos cursos mais concorridos da Universidade Federal de Sergipe (UFS). Os resultados indicaram atitudes muito contrárias às 
cotas, sobretudo às raciais. Depois da implantação, a oposição cresce para as cotas raciais e diminui para as sociais. Antes da implantação, os contrários afirmaram, sobretudo, que as cotas aumentavam o preconceito contra os negros; depois da implantação, a principal justificativa foi a de que elas discriminavam. Esses resultados são discutidos como indicadores das relações entre as ideologias do paternalismo e do senso de posição grupal no preconceito racial do Brasil.

Palavras-chave: cotas raciais e sociais; posição dos grupos; ameaça; preconceito.

The introduction of quotas in university: paternalism and threat to the position of the dominant groups

We conducted two studies in order to analyze the manifestation and development of attitudes towards quotas. Study $1(N=220)$, carried out five years before the implementation of quotas, indicated that students were very opposed to quotas, especially to the racial ones. In Study 1, the argument most often used to justify being against quotas was that they increase the prejudice against blacks. Study $2(N=114)$, conducted two months after implementation, indicated that opposition to racial quotas increased, while the opposition to social quotas decreased. Importantly, after the implementation of the quota system, the main reason to be against quotas was that they are a discriminatory measure. These results are discussed as indicators of the relations between the ideologies of paternalism and the sense of group position in racial prejudice in Brazil.

Keywords: racial and social quotas; position of groups; threat; prejudice.

\section{La introducción de cuotas en la universidad: paternalismo y amenaza a la posición de los grupos dominantes}

A fin de comprender cómo se manifiestan y desarrollan las actitudes hacia las cuotas bicimos dos estudios, uno antes y otro después de la implantación de las cuotas en la universidad. Participaron 334 estudiantes de los cursos más concurridos en la Universidad Federal de Sergipe. Los resultados muestran actitudes muy contrarias a las cuotas, especialmente las raciales. La oposición a las cuotas raciales aumenta y a las sociales disminuye después de su implantación. Antes de la implantación la justificación para las actitudes contrarias era, sobre todo, que las cuotas aumentan los prejuicios contra los negros; después de la implementación la razón principal fue la creencia de que ellas discriminan los grupos. Estos resultados se discuten como indicadores de las relaciones entre las ideologías de paternalismo y del sentido de la posición del grupo en el prejuicio racial en Brasil.

Palabras clave: cuotas raciales y sociales; posición social de los grupos; amenaza; prejuicio. 